\title{
Benign Liver Lesions: AClinical Profile
}

\author{
Mirat Dholakia ${ }^{1}$, Iqbal Ali ${ }^{2}$, Vashisht Dixit $^{3}$, Kshitij Manerikar ${ }^{4}$ \\ ${ }_{1,2,3,4}$ General Surgery, D.Y.Patil Medical College, Pimpri-Pune, India
}

\begin{abstract}
The diagnosis of benign liver lesions have been increased due to current imaging modalities and liver function test. Early detection of benign liver lesions by various imaging modalities of liver function test (LFT) can be treated by non-invasive methods. Benign liver lesions include a broad spectrum of pathologies ranging from regenerative nodules to true neoplastic processes and various cystic lesions. In this study, 50 cases were studied, age ranging from 19 years to 86 years. Age wise distribution of cases in study group showed that majority of cases were between 21-30 years age group. Amoebic liver abscess is the commonest lesion, which is common in males of 21-40 years. Cavernous hemangioma is the commonest solid lesion with female to male ratio of 2:1. Ultrasonography (USG) is the primary initial investigation in diagnosing benign lesions.
\end{abstract}

Keywords: Awareness, Benign, Hepatomegaly, Liver Abscess, Liver Lesions

\section{Introduction}

Liver isusually associated with malignant tumoursthat could beprimary,or metastatic depositsfrom primary elsewhere in thebody. With increased use of ultrasonography (USG) and other imagingmodalities,benign lesionsof liver are beingincreasingly diagnosed. The other advantageis that infectivelesionsare beingdiagnosed in earlier stagesand are thus amenable to non-invasivemanagement.They may be detected on imagingstudies incidentally, or during investigationof abnormal liver function testsor abdominal pain.

Benign hepatic tumoursincludeabroad-spectrum of pathologiesrangingfrom regenerative nodules to trueneoplasticprocesses.Thediagnosisof solid tumourswasa dilemma in recent past, but thanks to advancesin imagingstudies suchascontrastenhanced computed tomography (CECT) and magneticresonanceimaging(MRI)aswell asprogress in immunohistochemistry(IHC), accurate diagnosiscan bemadein a large percentageof patientswithout laparotomyor resection.

These tumourshavespecific featuresin variousimagingstudies. Themost common solid benign hepatic tumoursinclude cavernoushaemangioma, focal nodular hyperplasia, hepatic adenomaand nodular regenerative hyperplasia and cystic lesions like Simple liver cyst, pyogenic liver abscess, amoebic liver abscess and hydatid cyst. In themajority of casesof benign hepatic tumours, patientsareasymptomatic andno treatment isindicated initially. The main indication for treatment is thepresence of significant clinical symptomsor suspicion of malignancy or fear of malignant transformation.

Thisstudy wasundertaken to evaluate theclinical profile, incidence and epidemiology of benign liver lesionsin thecurrent settingof patient awarenessand widespread availability ofimproveddiagnostic modalities.

\section{Materials And Methods}

A total of fifty caseswere studied for aperiod of two years in a tertiary care teaching hospital. All casespresentingwith painin theright hypochondrium, hepatomegaly, jaundice or incidentally diagnosed lesion on USGor CTscan were included. Patientswith features of malignancy onUSG with or without CTscan,or evidence of aprimary lesion elsewhere in thebody were excluded.

Tables And Charts

\section{Sex wise distribution of cases in study group}

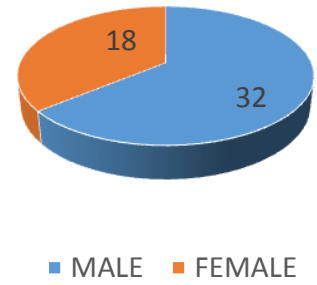

Table 1. Gender wise distribution of cases in study group 


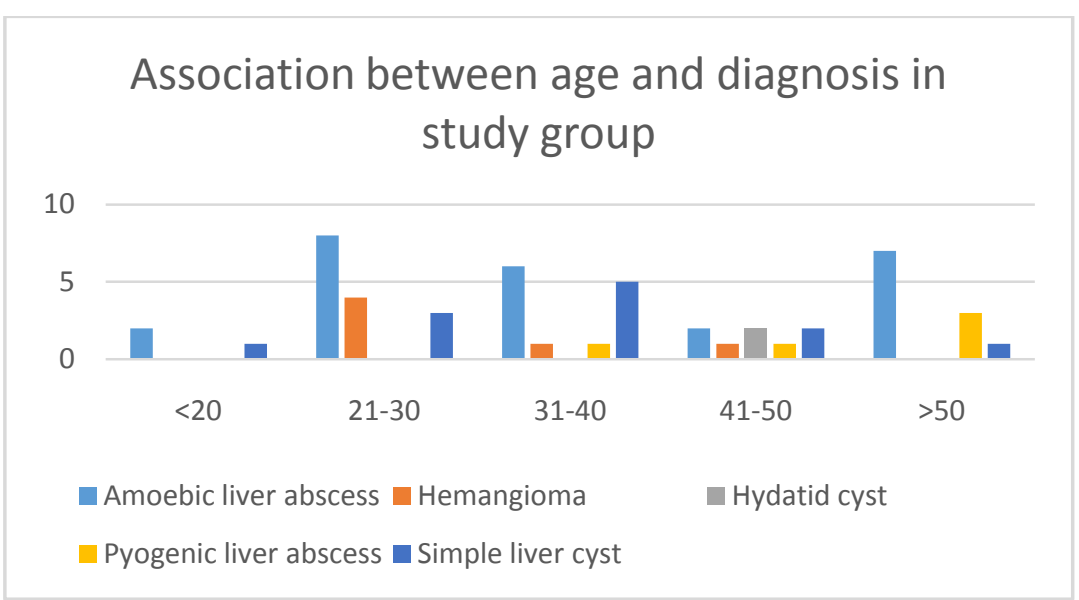

Table 2. Association between age and diagnosis in study group

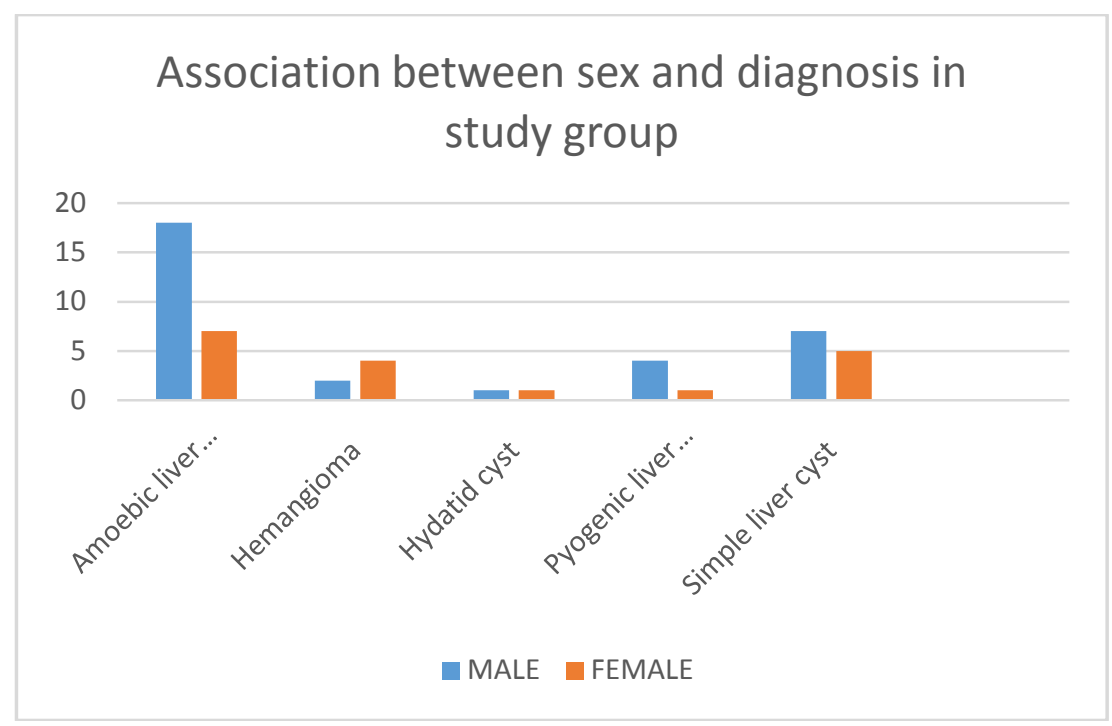

Table 3. Association between gender and diagnosis

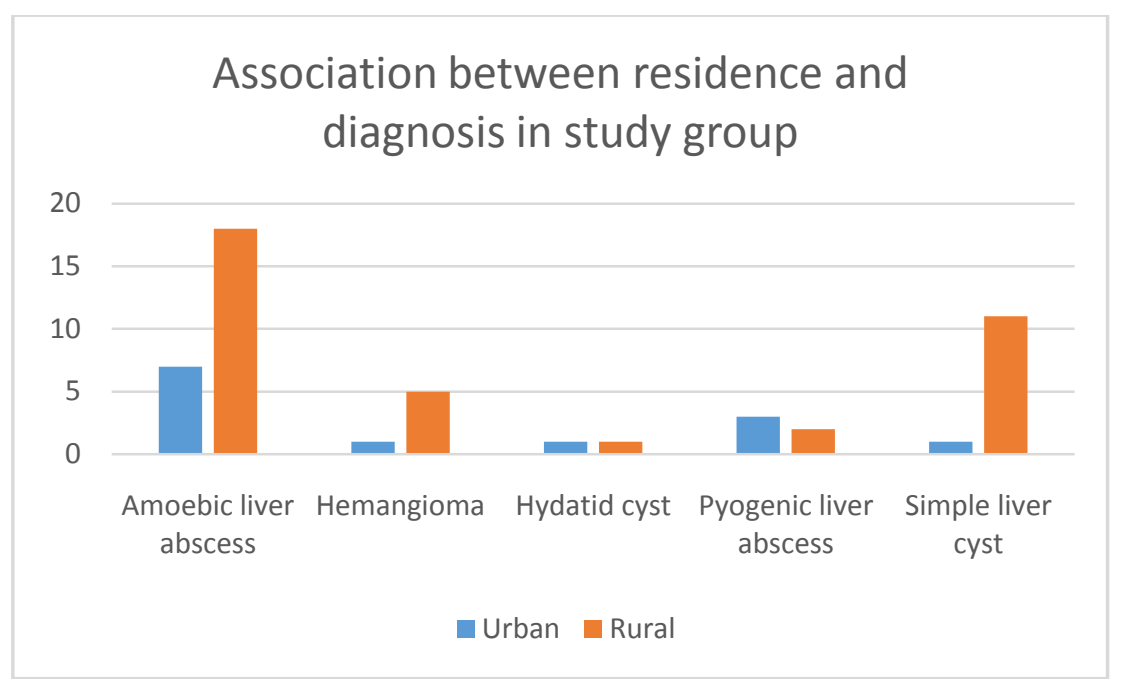

Table 4. Association between residence and diagnosis in study group 


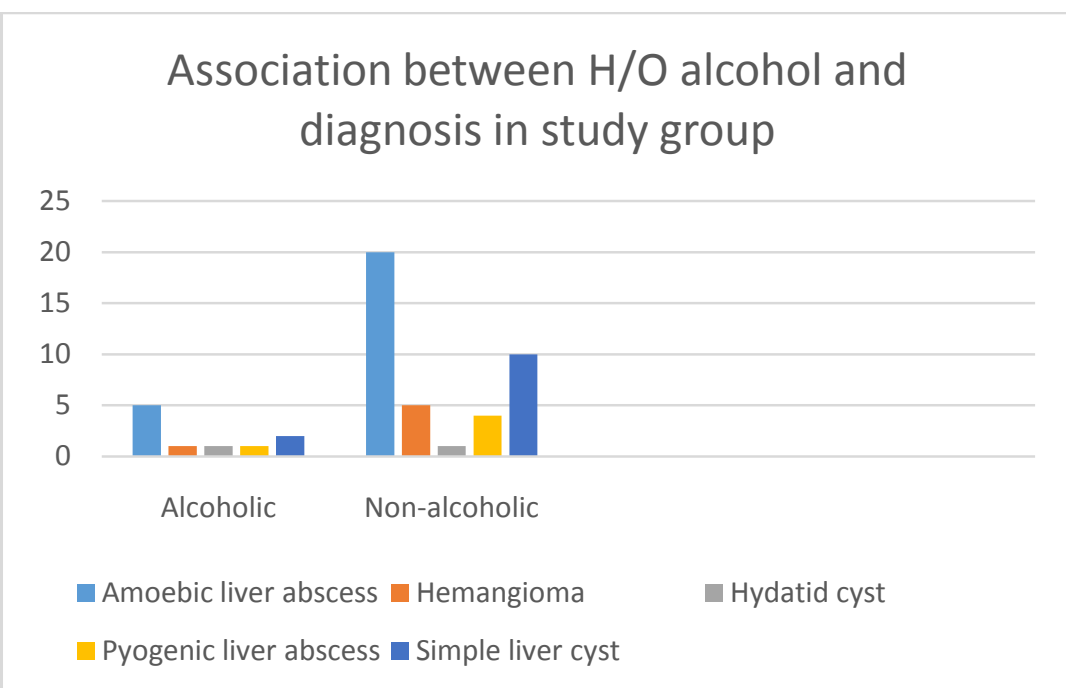

Table 5. Association between H/O Alcohol and diagnosis in study group

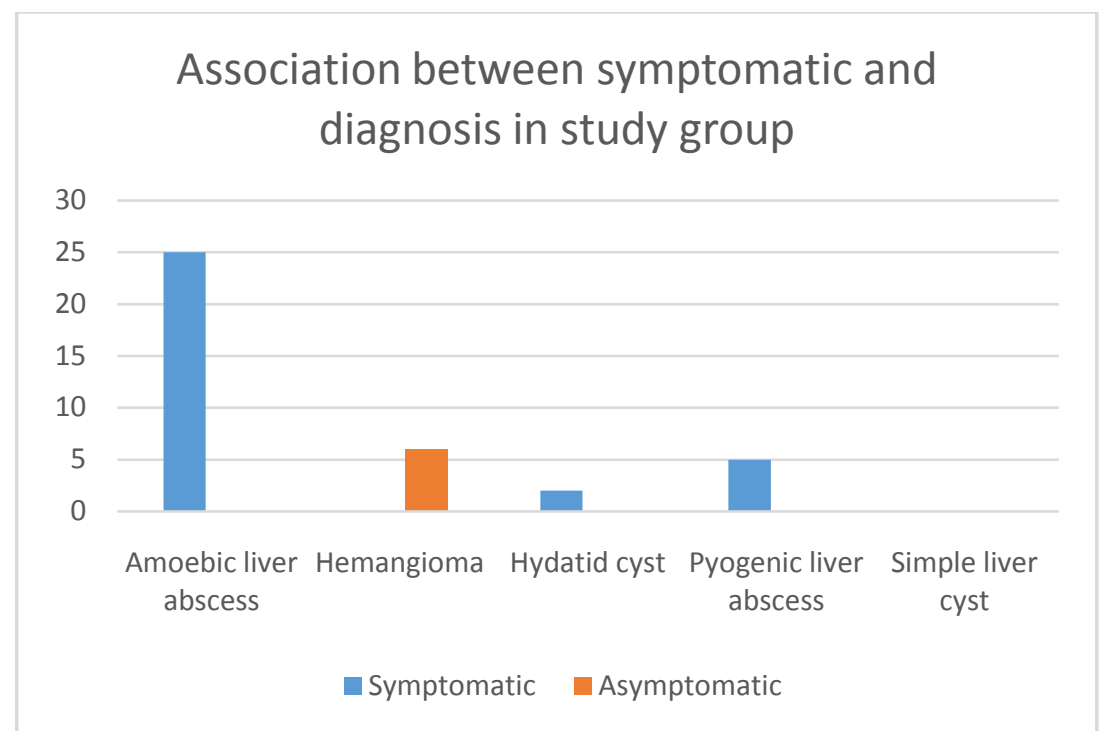

Table 6. Association between clinical features and diagnosis in study group

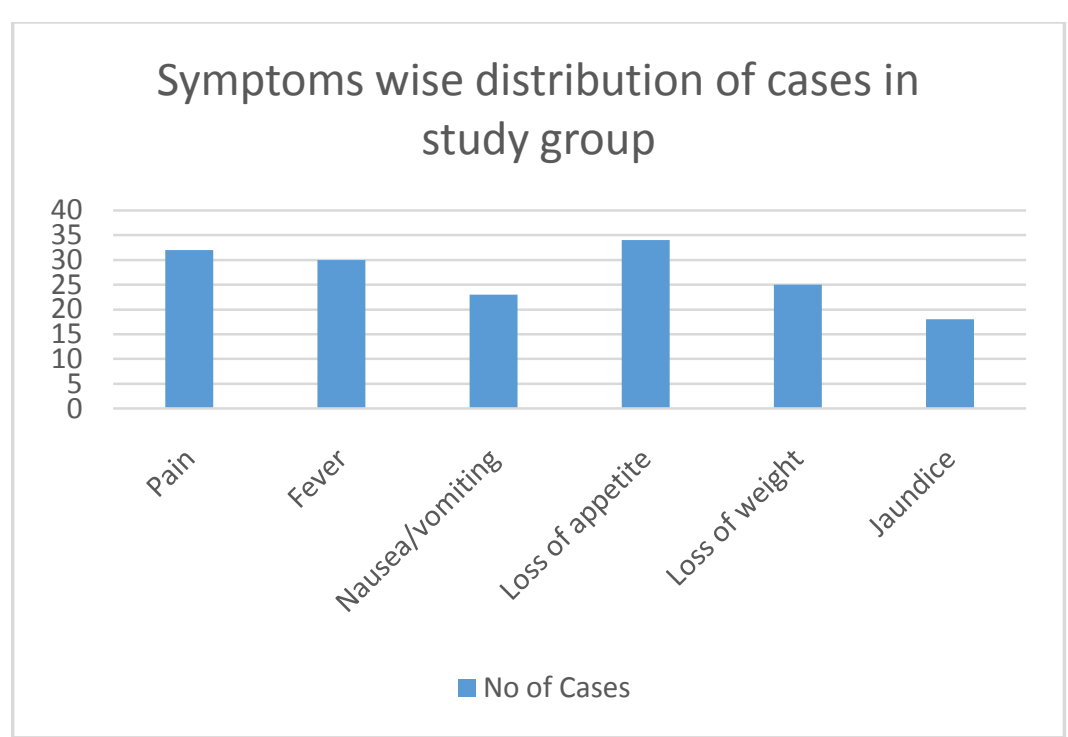

Table 7. Symptoms wise distribution of cases in study group 


\section{Association between symptoms and diagnosis in study group}

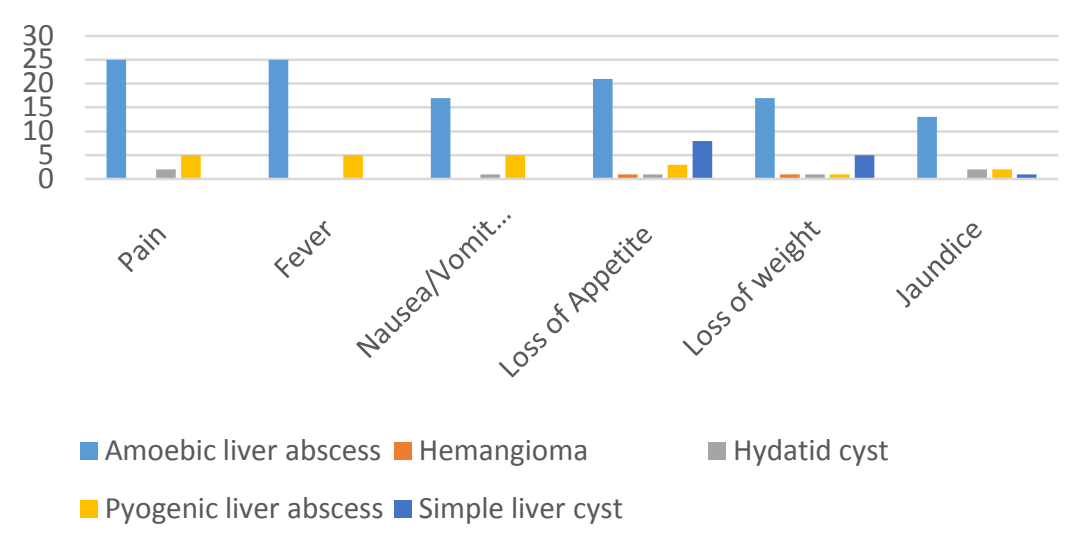

Table 8. Association between symptoms and diagnosis in study group

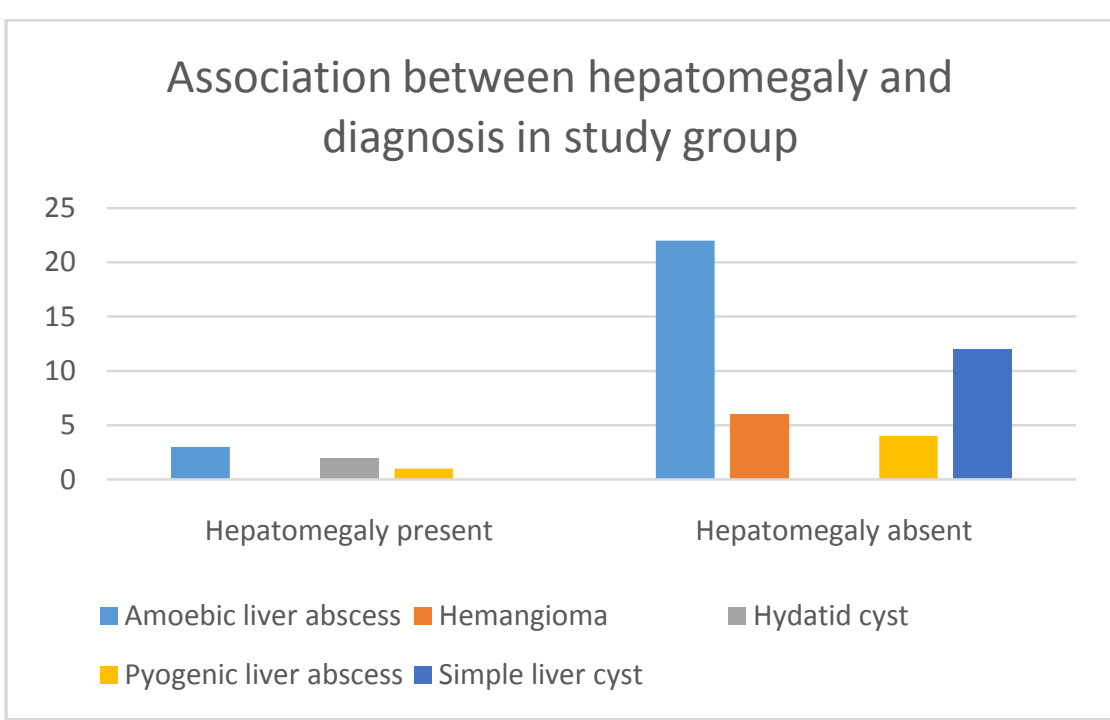

Table 9. Association between hepatomegaly and diagnosis in study group

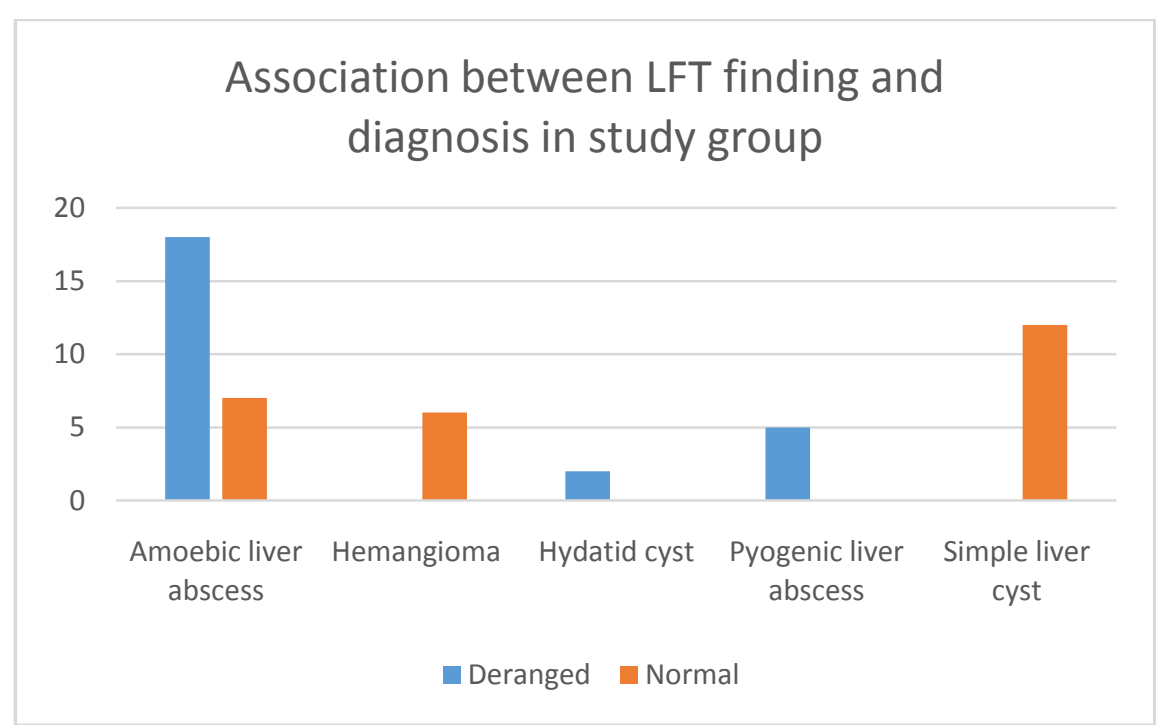

Table 10. Association between LFT finding and diagnosis in study group 


\section{Comparison of total, direct and PT-INR} according to diagnosis in study group

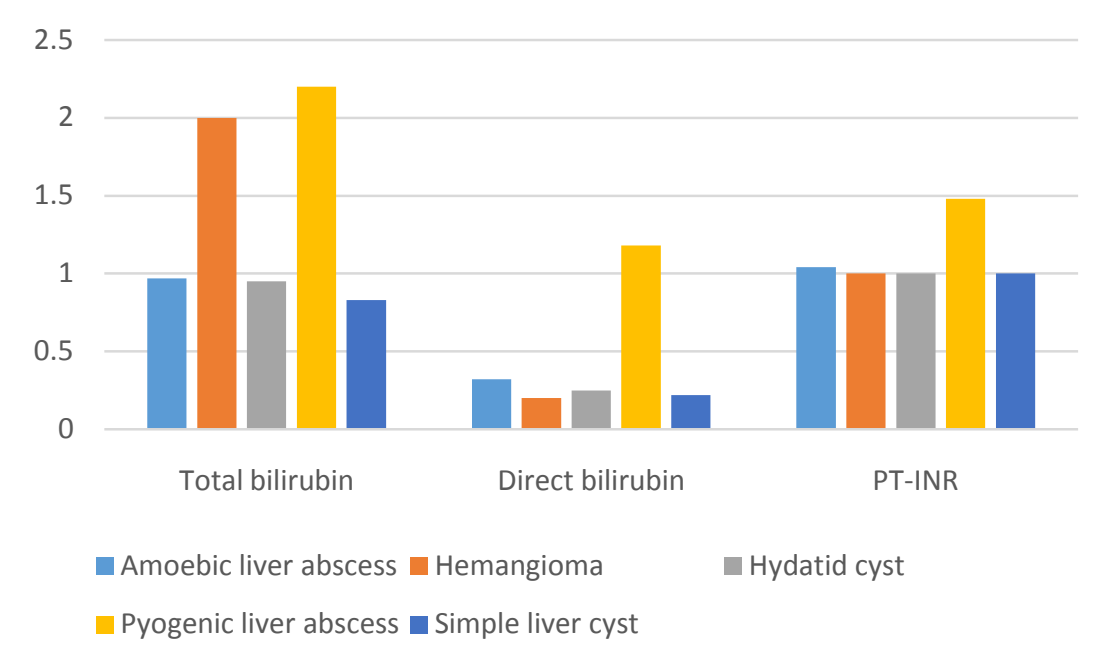

Table 11. Comparison of total, direct and PT-INR according to diagnosis in study group

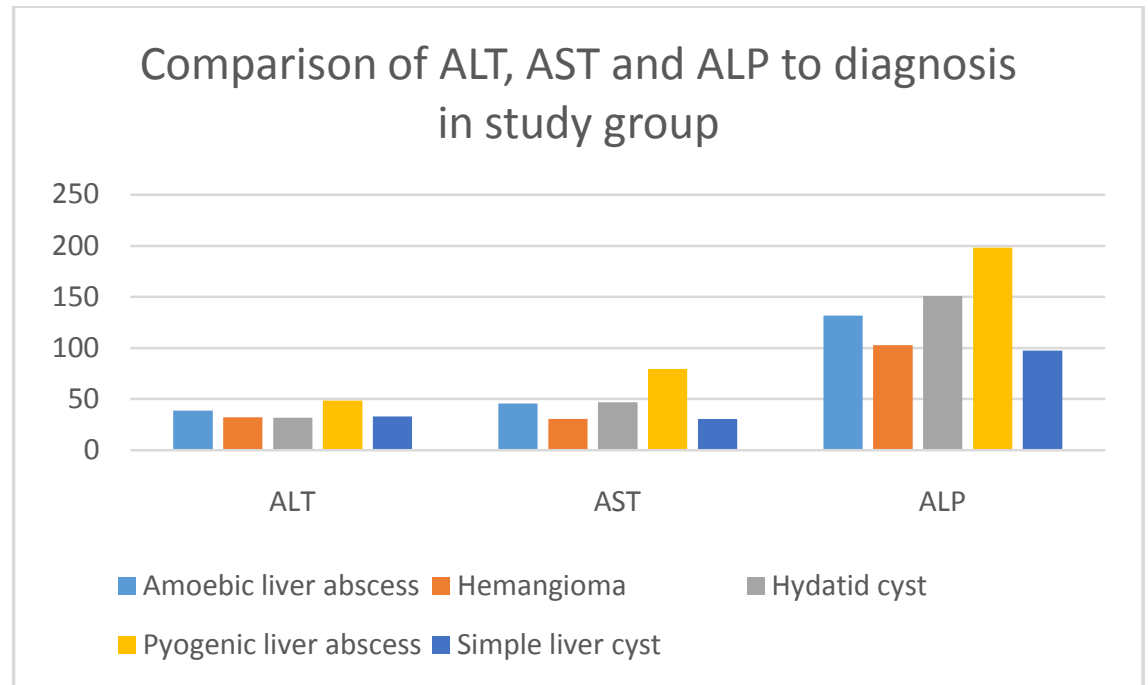

Table 12. Comparison of ALT, AST and ALP to diagnosis in study group

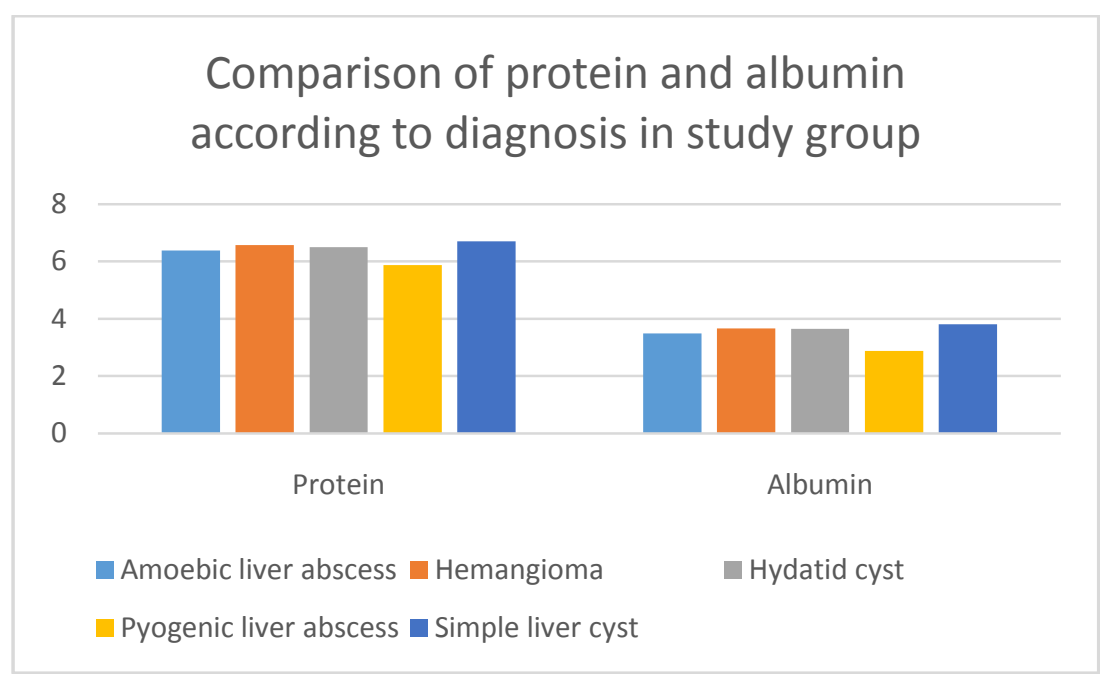

Table 13. Comparison of serum protein according to diagnosis in study group 


\section{Discussion}

In our study, 50 cases were studied. The age group of subjects ranged from 19 years to 86 years. The age wise distribution of cases in study group showed that majority of cases ( 15 cases) were in between 21 to 30 years age group, 13 cases were in age group of 31 to 40 years, 8 cases were in age group of 41 to 50 years and 11 cases were in age group of more than 50 years. This is in accordance with study done by Ananthakrishnan et al, in which common age group affected of 21 to 30 yrs and 31 to 40 years.[1]

Numbers of males were more as compared with females in study group (Table 1). Similar finding was also seen in a study conducted by Ananthakrishna et al in which males (93\%) has higher incidence. [1]

\section{Amoebic Liver Abscess}

The incidence of amoebic liver abscess was $50 \%$ in our study (Table 2), which is quite high as compared to study done by Mathur et al and Seeto et al, in which incidence of amoebic liver abscess is $3-9 \%$ and 8.5 patients per 100,000 population respectively. [2][3] This can be explained by the fact that in our hospital majority of patients come from rural background.

In our study male were significantly more affected as compared to females (Table 3). Out of total 25 cases of amoebic liver abscess 18 (72\%) were male and 7(28\%) were female. This is in accordance with study done by Seeto et al, in which $75 \%$ cases of amoebic liver abscess were males.[3] Similar finding was observed in a study conducted by Onwuchekwa et al, $81.8 \%$ of the cases of amoebic liver abscess were males and (18.2\%) females.[4] Similar findings were observed in study done by Katzenstein et al in which amoebic liver abscess occurred predominantly in males (85\%).[50] Study done by Mathur et al also showed similar results. [2] In our study out of 25 cases of amoebic liver abscess, maximum cases were in age group of 21 to 30 and 31 to 40 years i.e. $14(56 \%)$ cases (Table 2). Similar findings were observed in study done by Mathur et al, in which common age group was 30 to 50 years.[2] In study done by Seeto et a1 mean age is 28 years, which is in accordance to ourstudy.[3] In study done by Sharma et al, mean age was 40 years. [5] Similar findings were also observed in study done by Rajak et al, in which average age was 35 years. [6]

In our study out of 25 cases of amoebic liver abscess 18 (72\%) cases were from rural area (Table 4), which is in accordance with study done by Mathur et al. [2]

In our study $5(20 \%)$ cases of amoebic liver abscess were alcoholic (Table 5), which is in contrast to study done by Mathur et a1 and Seeto et al, in which $70 \%$ and $43 \%$ cases were alcoholic.[3]

In our study all cases of amoebic liver abscess were symptomatic (Table 6,7,8). All cases had fever and pain in right hypochondrium, 17 had nausea/vomiting, 21 had loss of appetite and 13 had jaundice. Similar findings were observed in study done by Seeto et al, in which $72 \%$ patients had fever and pain in right hypochondrium, 64\% had nausea/vomiting and loss of appetite but jaundice was present in only $4 \%$ of cases. [7] Similar findings were observed in study done by Mathur et al, in which $83-87 \%$ had fever and pain in right hypochondrium.[2]

In our study $72 \%$ cases of amoebic liver abscess had deranged LFTs (Table 10). In study done by Wells et al deranged LFTs were found in $76 \%$ cases, which was in accordance to our study. [7]

In our study most cases of amoebic liver abscess had deranged liver enzymes, AST and ALP respectively. Among the 25 cases of amoebic liver abscess, the mean ALT, AST and ALP were 38.72, 45.68 and 131.84 respectively. The mean total bilirubin was 0.97 and mean PT INR was 1.04. The mean total protein and albumin were 6.39 and 3.49 respectively (Table 11,12,13), which is in accordance to the study done by Wells et al.[7]

in our study cyst/tropozoite were seen in stool examination of only 2 (8\%) cases of amoebic liver abscess, which was in accordance to study done by Haque et al. [8] in our study serological test for E. histolytica (lHA) was done in 19 cases of amoebic liver abscess, out of which 14 (56\%) cases were positive. This is in accordance with study done by Mathur et al. [2] in our study 22 (88\%) cases of amoebic liver abscess were diagnosed on USG, which is in accordance to study done by Seeto et al, in which $85 \%$ cases of amoebic liver abscess were diagnosed on USG. [3] In our study USG findings showed hypoechoic lesion in all cases, hepatomegaly in $11(44 \%)$ cases, right lobe was involved in $22(88 \%)$ cases, left lobe in $2(8 \%)$ cases, both lobes in $1(4 \%)$ case, single lesion in $21(81 \%)$ cases and multiple lesion in $4(16 \%)$ cases of amoebic liver abscess. Similar findings were observed in study done by Seeto et al, Mathur et al and Sharma et al. [2][3][5]

In our study USG guided aspiration was done in 14 cases of amoebic liver abscess, out of which 10 $(52.6 \%)$ cases demonstrated tropozoite of E.histolytica on microscopy which is in contrast to study done by Haque et al and Seeto et al in which tropozoite were demonstrated in $11 \%$ and $4 \%$ cases respectively. [3][8]

\section{Pyogenic Liver Abscess}

In our study, pyogenic liver abscess was diagnosed in 5 cases (10\%) (Table 2), which is in contrast to the study done by Huang et al and Pearce et al in which the incidence is 13 per 100,000 and 20 per 100,000 population. [9][10] 
In our study $3(60 \%)$ cases of pyogenic liver abscess were in age group of more than 50 years and 4 $(80 \%)$ cases of pyogenic liver abscess were males (Table 2,3). Similar findings were observed in study done by Lee et al, Rahimian et al and Huang et al in which the mean age was 62.2, 56.4 and 60 years respectively and male patients were $70 \%, 69.6 \%, 55 \%$ respectively. [9][11][12]

In our study, all cases of pyogenic liver abscess were symptomatic (Table 6,7,8) and fever, pain in right hypochondrium and nausea/vomiting were present in all cases of pyogenic liver abscess; loss of appetite and jaundice was present in 3 and 2 casesrespectively. Similar findings were observed in study done by Rahimain et al, Yinnon et al and Wang et al. [13[14][15]

In our study, LFTs were deranged in all cases of pyogenic liver abscess( Table 10,11,12,13). Among 5 cases of pyogenic liver abscess, the mean total bilirubin was 2.20 and mean PT INR was 1.48. The mean ALT, AST and ALP were 48.40, 79.60 and 198.40 respectively. Among 5 cases of pyogenic liver abscess, the mean total protein and albumin were 5.88 and 2.88 respectively. This was in accordance to studies done by Rahimain et al and Wang et al. [12][13]

In our study $4(80 \%)$ cases of pyogenic liver abscess were diagnosed on USG. USG findings were hepatomegaly, was present in $3(60 \%)$ of cases, both lobes were involved in $3(60 \%)$ cases, right lobe in $2(40 \%)$ cases and all were multiple abscesses. Among 5 cases of pyogenic liver abscess, 4 were hypoechoic and 1 had mixed echogenicity, 4 had round shape and regular border. There was no evidence of CBD and/or IHBR dilatation. This was in contrast to study done by Rahimain et al, in which right lobe involvement was $70.5 \%$ and $77 \%$ abscesses were solitary. [12]

In our study USG guided aspiration was done in all cases of pyogenic liver abscess. Aspirate culture was Klebsiella pneumoniae in $3(60 \%)$ cases and in $1(20 \%)$ case culture was E. coliand 1 case had polymicrobial growth, This was in accordance to study done by Wang et al, in which $87.9 \%$ of liver abscesses were caused by K. pneumonia. [13]

\section{Hemangioma}

Hemangioma was the most common solid benign hepatic lesion in our study with an incidence of $12 \%$ (6 patients) and male to female ratio of 2:1 (Table 2,3), which is in close correlation to the study of Gandolti et al and Trastek et al.[10][16] However this is lower than reported by the other workers who noted a female prevalence up to $5: 1$. [17][18]

In our study most cases of hemangioma were in age group 21 to 30 years (Table 2). Out of the 18 female patients in the study, hemangioma constituted the $22.2 \%$ of cases. In males, hemangioma compromised $6.25 \%$ of the total cases in male patients.

Majority of the patients were asymptomatic (66.6\%) and rest presented with nonspecific abdominal pain and anoxia (Table 6,7,8). Liver function tests were normal in all cases (Table 10,11,12,13). These findings are in accordance to the study done by Gandolh et al and Chamberlain et at. [16][19]

Majority of the lesions (66.6\%) were in the right lobe with the remainder in the left lobe and showed uniformly hyperechoic, on doppler study hemangioma findings were well demarcated lesion, increased vascular flow, central venous pooling and delayed central filling. All lesions were solitary. These findings correlated with study ofGandolfi et al and Beckingham et al. [16][20]

\section{Simple Liver Cyst}

In our study, there were $12(24 \%)$ cases of simple liver cysts with $5(10 \%)$ cases in the age group of 31 to 40 years (Table 2). Male:female was 1.4:1 (Table 3) as compared to study done by Spiegel et al, which showed female preponderance. [21]

Among 12 cases of simple liver cyst, all were asymptomatic (Table 6,7,8). Liver function tests were normal in all cases (Table 10,11,12,13). These findings are in accordance with study done by Mori et al. [22] Right lobe preference was noted in 8 (66.6\%) and 4 (33.3\%) in the left lobe. Sonographically, all cases of simple liver cyst were hypoechoic with round and regular shape and border with absence of internal structure, sharp smooth borders and strong posterior sonic transmission, which was consistent with Spiegel et al study and Anderson et al. [21][23]

\section{Hydatid Cyst}

In our study two cases (4\%) of hydatid cyst were noted, in the age group of 41 to 50 years (Table 2). Male: female ratio was 1:1 (Table 3). All cases presented with pain right hypochondrium and anorexia (Table 6,7,8). These findings are in accordance with studydone by Elshazly et al. [63] Among the liver function test, ALP was deranged in both cases (Table 10,11,12,13). Similar findings were observed in study done by Elshazly et al. [24] 
Right lobe was affected in both the cases. All the lesions were solitary. On ultrasound, they were complex cystic lesion with well-defined walls with multiple septa daughter cysts and internal echogenic matrix. These findings correlate with study done by Lewall et al. [25]

\section{Conclusion}

Incidence of benign lesions of liver is increasing. The physician in general and the surgeon in particular should be clear in his mind about its pathology and management.

Amoebic liver abscess continues to be the commonest infective lesion amongst the rural population, with high incidence in young males. Amongst the solid lesions cavernous hemangioma is the commonest with high incidence in females. In our study symptomatic lesions are more common than asymptomatic. Fever and right hypochondriac pain is the commonest symptom of infective cystic lesions. Hepatomegaly is the commonest presentation in case of hydatid cyst. Solid lesions are mostly silent and detected incidentally on USG. IHA test is highly sensitive in diagnosing amoebic liver abscess.

LFTs are deranged in case of liver abscess. Liver enzymes in case of amoebic liver abscess and bilirubin and liver enzymes in case of pyogenic liver abscess. USG is the primary investigation of choice, which can be confirmed by contrast enhanced CT scan or FNAC, depending upon the pathology.

\section{References}

[1]. Ramani A, Ramani R, Shivananda PG. Amoebic Liver Abscess. A Prospective Study of 200 Cases In A Rural Referral Hospital In South India. Bahrain Medical Bulletin 1995;17(4):1-4.

[2]. Mathur S, Gehlot RS, Mohta A, Bhargava N. Clinical Profile of Amoebic Liver Abscess. JIACM 2002; 3(4):367-73.

[3]. Seeto RK, Rockey DC. Amoebic liver abscess: epidemiology, clinical features, and outcome. West J Med 1999; 170(2):104-9.

[4]. Onwuchekwa AC, Onwuchekwa RC. Clinical and ultrasonographic features of amoebic liver abscess in a nigerian teaching hospital Sahel Medical Journal 2009; 12(3):117-21.

[5]. Jiang H, Chen Z, Prasoon P, Wu H and Zeng Y. Surgical Management for Giant liver Hemangiomas Greater Than $20 \mathrm{~cm}$ in Size. Gut and Liver 2011; S(2):228-233.

[6]. Rajak CL, Gupta S, Jain S, Chawla Y, Gulati M, Suri S. Percutaneous treatment of liver abscesses: Needle aspiration versus catheter drainage. Am J Roentgenol 1998; 170(4):1035-1039.

[7]. Wells CD, Arguedas M. Amoebic liver abscess. Southern Medical Journal 2004; 97(7):673-82

[8]. Haque R, Mollah Nu, Ali 1K, Alam K, Eubanks A, Lyerly D \&Petri W. Diagnosis of Amoebic Liver Abscess and Intestinal Infection with the TechLab Entamoeba histolyticall Antigen Detection and Antibody Tests. J. Clin. Microbiol 2000; 38(9):3235-39

[9]. Huang CJ, Pitt HA, Lipsett PA, Osterman FA, Lillemoe KD, Cameron JL et al. Pyogenic hepatic abscess: Changing trends over 42 years. Ann Surg 1996; 223(5):600-9.

[10]. Trastek VF, Van Heerden JA, Sheedy PF, Adson MA. Cavernous hemangiomas of the liver: resector observe? Am J Surg 1983;145:49-53.

[11]. LeeNK. Kim S. Lee JW, Jeong YJ. Lee SH, Heo J \& KangDH. CTDifferentiation ofpyogenic liver abscessescausedbyKlebsiellapneumoniaevs Non-klebsieIIa pneumonia.Br J Radiol. 2011 June;84(1002):518-525.

[12]. Rahimian J, Wilson T, Oram V\&Holzman RS. Pyogenic Liver Abscess: recent trends in etiology and mortality. Clin Infect Dis 2004; 39(11):1654-9.

[13]. WangJH, Liu YC, Lee SS, Yen MY, ChenYS, WannSR, Lin HH. Primary LiverAbscessDue to KlebsiellapneumoniaeinTaiwan.Clin InfectDis 1998; 26: 1434-8.

[14]. Yinnon AM, Halpcrn IH, ShapiroM \& HershkoC. The changing clinical Spectrumof liver abscess:the Jerusalemexperience.PostgradMed J 1994; 70(824):436 - 439.

[15]. Pérez JAA, Gonzalez JJ, Baldonedo RF, Sanz L, Carreno G, Junco A et al. Clinical course, treatment, and multivariate analysis of risk factors for pyogenic liver abscess. The American Journal of Surgery 2001;181(2):177-186.

[16]. Gandolfi L.LeoP,Solmi L, Vitelli E, Verros G, Colecchia A.Natural historyof Hepatichemangiomas:clinicalandultrasoundstudy. Gut $1991 ; 32: 677-680$

[17]. Shumaker HB Jr. Hemangioma of the liver: discussion of the symptomatology and report of patient treated by operation. Surgery 1942;11:209-222.

[18]. Henson SW, Gray HK, Dockerty MB. Benign tumors of the liver. Hemangiomas. SurgGynecolObstet 1956; 103:327-331.

[19]. Chamberlain RS, DeCorato D, Jamagin WR. Benign Liver Lesions. [Accessedon July 24 2013]. Available from: http://web.squ.eduom/med-Lib/MED_CD/E_CDs/ Hepatobiliary\%20Canoa/ DOCSCh] .pdf

[20]. Beckingham J, Kraig J. Ryde SD. ABC of disease of liver pancreas and biliary tract. Br Med J 2001; 23:33-36.

[21]. Spiegel RM, King DL, Gream WM. Ultrasonography of primary cysts of the liver. Am J Roentgenol 1978; 131:235-238.

[22]. Mori E, Akai Y, Matsumoto T, Kawaratani H, Horii M,Iwano M et al. Hepatic cyst infection in a healthy older male. BMJ Case Reports 2012; doi:10.1136/bcr.04.2011.4136.

[23]. Anderson SW, Kruskal J B, Kane RA. Benign Hepatic Tumors and Iatrogenic Pseudotumors. RadioGraphics 2009; 29:211-229.

[24]. Elshazly AM, Azab MS, ElBeshbishi SN, Elsheikha HM. Hepatic hydatid disease: four case reports. Cases Journal 2009;2:58doi:10.1186/17571626-2-58.

[25]. Lewall DB, McCorkell SJ. Hepatic echinococcal cyst: sonographic appearance and classification. Radiology 1985; 1551773-5 